\title{
Supporting Families having a Child with Intellectual Disability in COVID-19 Pandemic
}

\author{
Arusa Lakhani ${ }^{1 *}$ Debbie Krammer ${ }^{2}$ and Tazeen Saeed $\mathrm{Ali}^{3}$ \\ ${ }^{1}$ School of Nursing and Midwifery, Aga Khan University, Pakistan \\ ${ }^{2}$ Amsterdam University of Applied Sciences, Netherlands \\ ${ }^{3}$ Associate Professor and Assistant Dean Research, Aga Khan University School of \\ Nursing and Midwifery, Karachi \\ *Corresponding Author: Arusa Lakhani, School of Nursing and Midwifery, Aga \\ Khan University, Karachi, Pakistan.
}

\begin{abstract}
The COVID-19 pandemic has devastating effects on the lives of the children and their families who have member with an intellectual disability. In such a distressing situation and uncertainties due to the pandemic, the relationships among the family members can become unpleasant, affecting support and cohesiveness within the family, which may have a negative effect on the child. Lack of support and socialization of these families, lead to a stress among them especially for the immediate carers. In a lockdown situation, their routine is disrupted and the parents have to pay extra attention to care for the child. Some of the strategies that are proven to be helpful for the children with an intellectual disability and their families are accessing reliable and trusted information on COVID-19, allowing the child to express his/her feelings by engaging them in different activities, open and supportive interaction among family members, and maintaining the structured daily routine that they followed before the pandemic. The educators/trainers/staffs of the school must remain in touch with the family and inquiring from them "how they are". Telephonic or video -conferencing counseling and coaching can be offered to the family members and some important tips to overcome the stressors can be discussed. Hence, during lockdown, individualized home programs that can be carried out by family members with the child with an intellectual disability are a good way to ensure the child continues to develop their cognitive, movement, play and self-help skills. Moreover, the government cash transfer assistance should also reach those vulnerable families who have the children with disabilities. It may bring some relief to the families who are struggling to balance their finances to ensure meeting the basic needs.
\end{abstract}

Keywords: Intellectual Disability; Family Support; COVID-19

\section{Introduction}

This paper highlights the need for support to families with children with intellectual disabilities (ID) amid Pandemic. It also presents some practical tips, based on the knowledge that I have as a PhD Scholar working in the same area that is social support for these families and my experiences of living with a family member, who has an intellectual disability.

The COVID-19 pandemic has devastating effects on the lives of the children and their families. The daily routines and usual roles and responsibilities have altered. Families are facing increased fear and uncertainties about the future during this pandemic and are exploring ways to create a safe and peaceful environment [1]. In the Pakistani context, family is considered as a unit with strong and all-weather binding, where we believe in jointly addressing the difficulties and worries and celebrating occasions by sharing happiness with each other. According to Zuna, Brown, and Brown [2], "regardless of how a family is defined across cultures, they have similar needs e.g. food, healthcare, social relationships and care for children... ensuring that those families who have a child with an intellectual disability have access to required resources and supports". The families who have a member with an intellectual disability undergo stressful experiences raising a child and they are 
often marginalized [3-6] and face difficulty in accessing resources [7] including social support.

In such a distressing situation and uncertainties due to the pandemic, the relationships among the family members can become unpleasant, affecting support and cohesiveness within the family, which may have a negative effect on the child. Lack of support and socialization of these families, lead to a stress among them especially for the immediate carers. Families with a child with an intellectual disability, need to identify and seek support, often from within the family. Postan., et al. [8] stated that "these parents lamented the fact that they frequently felt tethered to their child and simply could not make spontaneous plans to go out of their house... in some cases, even out of the room". Such unhealthy and stressful situation and lack of support has an undesirable effect on the parent-child interaction including his/her development [9]. It can also lead to domestic violence, which can divert more towards these children, who are vulnerable and are often completely dependent on the family members or caretaker. Researches are reporting an increase in domestic violence and child abuse and neglect including people with disability around the globe during this COVID-19 pandemic due to social distancing, economic stress and limited travel [10-13].

In a lockdown situation, those children who were going to the daycare school or moving out for some activities, are now mostly at home and are staying with the family members. Hence, their routine is disrupted, and the parents have to pay extra attention to care for the child. Those children who can read and write, may get connected and find some entertainment online, but the face to face link with their facilitators, friends and colleagues is interrupted. Though this may be temporary, such separation from family and friends can be very stressful for these children and their families, which may lead to distress and anxiety [13]. In addition, the economic crisis and the commercial downfall which is all over the world, has severely affected most of the families and has put additional financial pressures on these families [13,14]. Meeting the needs of the family and managing expenses, is creating many challenges for the cares leading to a taxing circumstances that affect their mental health [14].

\section{Support for the families with an intellectually disabled child}

Adequate social support for families with children with an intellectual disability is associated with satisfaction of the life [15]. Social support can be formal, which is received from profession- als, or informal from the family and friends [16]. Both these forms of support are considered necessary, to help the family positively cope, and adjust [17], lessen their fears and reservations, and allow them to learn that they are not alone, in order to lead them to hope rather than stress. In Pakistan, the families mainly receive their support from informal sources such as spouses, relatives, personal faith or through friends in their religious community, rather than from formal sources [18]. Those families, who receives higher levels of support, are more likely to be cohesive and learn problem solving skills, which positively influence the child [19]. Adequate support within the family and the community is essential to lead safe, healthy and independent lives, but due to the spread of COVID-19, there is a significant disruptions to services, support systems and informal networks [20]. United Nations [20] further emphasize that if the support for these families is missing in this pandemic, it can have a negative effect on both the person with disabilities and the other family members. In Pakistan, families have their own way of attaining social support, which is embedded in their own larger family or community system. Amid pandemic and lock down situation, created tough situation in the family due to lack of socialization, inadequate finances and disturbed routine, leading to stress and anxiety among the family members including the child. According to Courtenay and Perera [21], lack of outdoor activity, disturbed routines and usual life style may cause stress, irritability and other neuropsychiatric related symptoms.

\section{Strategies for strengthening support in COVID-19 pandemic}

The COVID-19 pandemic has impacted lots of individuals and their families. At family level, in this challenging time, it is important that an adequate level of communication among the family members is maintained. Additionally, the relevant information on the current pandemic needs to be shared with the child based on his/her level of understanding and comprehension. Few of the examples on COVID-19 information, specifically designed for the children with an intellectual disability, using simple language and clear pictures or symbols, can be retrieved from by www.mencap.org.uk [22] or www.kids.org.uk [23]. Such easy to understand and read information on measures for keeping the children and family safe, ways of engaging these children at home amid COVID-19 with practical tips to follow, can be translated into the Urdu Language and can be communicated with the families, who could then share it with their children. WHO [24] emphasized, that the families should limit receiving unnecessary information from the media regarding COVID-19, as not all of this information is correct, which can affect mental wellbeing. Instead they should focus only on informa- 
tion that can be trusted and is helpful from the reliable sources like WHO, or government reports. Staying in quarantine is likely to be very tough for people with an intellectual disability, as they may not understand its importance [21]. Allowing the child to express his/ her feelings by engaging them in different activities such as drawings can make them feel relieved [24]. Families within themselves, can ensure open and supportive interaction, so that everyone in the family maintains cohesiveness in this difficult time. The members of the family can try to maintain the structured daily routine that they followed before the pandemic, to minimize disruptions in the day to day work $[24,25]$. Based on the capacity and capability, the child can be involved in daily household chores, so that they can have a positive experience of feeling part of the family. Besides this, the child who has additional underlying health issues, and is more prone to contract infections because of comorbidities [21], should be properly fed to meet the daily nutritional requirements and to have an adequate energy to combat infections.

In addition, Coyne ${ }^{1}$ points out that: "On an airplane, when there is an emergency, parents are told to put on their own oxygen masks first so that they can effectively support their children and keep them safe. In the time of this pandemic, practitioners must thus teach parents how to care for themselves if they are to expand their ability to nurture their children through adversity".

At the community level, if children were going to day care institution, it's important that their educators/trainers/staffs remain in touch with the family and inquiring from them "how they are". Telephonic or video -conferencing counseling and coaching can be offered to the family members and some important tips to overcome the stressors can be discussed [25]. If required, the family members can be provided with an online consultation or the medical help. During lockdown, individualized home programs that can be carried out by family members with the child with an intellectual disability are a good way to ensure the child continues to develop their cognitive, movement, play and self-help skills [26,27]. The family may feel supported with such efforts and it can strengthen the informal support system lies within the family; leading to positive and healthy coping in COVID-19.

The families continue to struggle to socialize and gain social support. The literature illustrates the need of social support that permits inclusion of these families with their child in the community and society at large [28]. Therefore, the support services should be responsive to the needs of the family in which they are living [29]. Moreover, the government cash transfer assistance should also reach those vulnerable families who have the children with disabilities. In April 2020, Prime Minister of Pakistan, announced the Emergency Cash Program named 'Ehsaas' worth Rs. 144 billion to disburse to around 12 million beneficiaries who are economically affected by the COVID-19 pandemic [30]. Hence it is critical that these families should be included in the list of beneficiaries not by chance but with a strong intention to support these families. It may bring some relief to the families who are struggling to balance their finances to ensure meeting the basic needs.

\section{Conclusion}

In conclusion, it is extra important that families with children with an intellectual disability continue to receive support and guidance during this Covid-19 pandemic. Forms of support include reliable, easy to understand and correct information about Covid-19, a listening ear and practical advice about home-based activities to keep the child with an intellectual disability settled and able to engage in meaningful and educational activities to stay safe and healthy.

\section{Conflict of Interest}

No conflict of interest.

\section{Bibliography}

1. Coyne LW., et al. "First things first: Parent psychological flexibility and self-compassion during COVID-19". Behavior Analysis in Practice (2020): 1.

2. Zuna NI., et al. "Family quality of life in intellectual and developmental disabilities: a support-based framework". International Public Health Journal 6.2 (2014): 161.

3. Blue-Banning M and Turnbull AP. "Hispanic youth /young adults with disabilities: Parents' vision for the future". Research and Practice for Persons with Severe Disabilities 27.3 (2002): 204-219.

4. Crnic KA., et al. "Intellectual disability and developmental risk: Promoting intervention to improve child and family well-being". Child Development 88.2 (2017): 436-445.

5. Eisenhower AS., et al. "Preschool children with intellectual disability: syndrome specificity, behaviour problems, and maternal well-being". Journal of Intellectual Disability Research 49.9 (2005): 657-671. 
6. Luijkx J., et al. "Time use of parents raising children with severe or profound intellectual and multiple disabilities". Child: Care Health and Development 43.4 (2017): 518-526.

7. Lippold T and Burns J. "Social support and intellectual disabilities: A comparison between social networks of adults with intellectual disability and those with physical disability". Journal of Intellectual Disability Research 53 (2009): 463-473.

8. Postan D., et al. "Family quality of life: A qualitative inquiry". Mental Retardation 41.5 (2003): 313-328.

9. Collins PY., et al. "Global services and support for children with developmental delays and disabilities: Bridging research and policy gaps". PLoS Medicine 14.9 (2017): e1002393.

10. Usher K., et al. "Family violence and COVID-19: Increased vulnerability and reduced options for support”. International Journal of Mental Health Nursing (2020).

11. Campbell AM. "An increasing risk of family violence during the Covid-19 pandemic: Strengthening community collaborations to save lives". Forensic Science International: Reports (2020): 100089.

12. Chandan JS., et al. "COVID-19: a public health approach to manage domestic violence is needed". The Lancet Public Health 5.6 (2020): e309.

13. Douglas M., et al. "Mitigating the wider health effects of covid-19 pandemic response". British Medical Journal 369 (2020): m1557.

14. Fegert JM., et al. "Challenges and burden of the Coronavirus 2019 (COVID-19) pandemic for child and adolescent mental health: a narrative review to highlight clinical and research needs in the acute phase and the long return to normality". Child and Adolescent Psychiatry and Mental Health 14 (2020): 1-11.

15. Hina AH., et al. "Parental satisfaction with life and perceived social support of parents of children with intellectual disability". International Journal of Innovation and Scientific Research 20.2 (2016): 398-402.

16. Azar M and Badr LK. "Predictors of coping in parents of children with an intellectual disability: comparison between Lebanese mothers and fathers". Journal of Pediatric Nursing 25.1 (2010): 46-56.
17. Beighton $\mathrm{C}$ and Wills J. "Are parents identifying positive aspects to parenting their child with an intellectual disability or are they just coping? A qualitative exploration". Journal of Intellectual Disabilities 21.4 (2017): 325-345.

18. Sheikh MH., et al. "Psychiatric morbidity, perceived stress and ways of coping among parents of children with intellectual disability in Lahore, Pakistan". Cureus 10.2 (2018).

19. Lardieri LA., et al. "Sibling relationships and parent stress in families of children with and without learning disabilities". Learning Disability Quarterly 23 (2000): 105-116.

20. United Nations. Policy Brief: A Disability-Inclusive Response to COVID-19 (2020).

21. Courtenay K and Perera B. "COVID-19 and People with Intellectual Disability: impacts of a pandemic". Irish Journal of Psychological Medicine (2020): 1-21.

22. Mencap: The Voice of Learning Disability. Information about Coronavirus (COVID-19) (2020).

23. Kids: Giving Disabled Children a Brighter Future. Coronavirus: Useful information for the parents and Carers (2020).

24. World Health Organization. "Mental health and psychosocial considerations during the COVID-19 outbreak" (2020).

25. Narzisi A. "Handle the autism spectrum condition during Coronavirus (COVID-19) stay at home period: Ten tips for helping parents and caregivers of young children". Brain Science 10.4 (2020): 207.

26. Wuang YP., et al. "Occupational therapy home program for children with intellectual disabilities: A randomized, controlled trial". Research in Developmental Disabilities 34.1 (2013): 528537.

27. Rickards AL., et al. "A randomized, controlled trial of a homebased intervention program for children with autism and developmental delay". Journal of Developmental and Behavioral Pediatrics 28.4 (2007): 308-316.

28. McLaughlin D Adams., et al. "Factors which enhance or inhibit social support: A mixed-methods analysis of social networks in older women". Ageing and Society 31.1 (2011): 18-33.

29. Imran N., et al. "Frequency of ICD-10 psychiatric diagnosis in children with intellectual disability in Lahore, Pakistan and Caregivers Perspective". Pakistan Journal of Medical Sciences 31.2 (2015): 285. 
30. World Bank in Pakistan: COVID-19 (Coronavirus) response (2020).

\section{Assets from publication with us}

- Prompt Acknowledgement after receiving the article

- Thorough Double blinded peer review

- Rapid Publication

- Issue of Publication Certificate

- High visibility of your Published work

Website: www.actascientific.com/

Submit Article: www.actascientific.com/submission.php

Email us: editor@actascientific.com

Contact us: +919182824667 